\title{
Juvenile muscular atrophy of the distal upper limb (Hirayama disease) associated with atopy
}

\author{
J Kira, H Ochi
}

\begin{abstract}
Juvenile muscular atrophy of the distal upper limb (Hirayama disease) is a rare disease predominantly affecting the anterior horn cells of the cervical spinal cord in young men. Although the disease is considered to be a type of cervical myelopathy, the mechanism remains unknown. An immunological study of five consecutive patients with this disorder who were examined in the neurology clinic at Kyushu University Hospital during the past 2 years were performed. All developed distal muscular atrophy and weakness of one or both upper limbs in the second decade, and showed forward displacement of the dural sac and passive dilatation of the posterior venus plexus at the lower cervical portion on MRI during neck flexion. Four of the five patients had one or more coexistent airway allergies, such as allergic rhinitis, pollinosis, and asthma, and all five patients had a family history of atopic or allergic disorders in close relatives. Four of the five patients had mild eosinophilia. All five patients commonly had IgE specific to two mite antigens, Dermatophagoides pteronyssinus and Dermatophagoides farinae, whereas three of them also showed a raised total serum IgE concentration. The frequency of mite antigen specific IgE was significantly higher in the present patients with Hirayama disease than in 82 healthy controls $(26 / 82, p<0.005)$. These findings suggest that atopy may be one of the contributing factors for Hirayama disease. (F Neurol Neurosurg Psychiatry 2001;70:798-801)
\end{abstract}

Department of Neurology,

Neurological Institute,

Graduate School of

Medical Sciences,

Kyushu University,

Fukuoka 812-8582,

Japan

J Kira

H Ochi

Correspondence to:

Professor J Kira

kira@neuro.med.kyushu-u.ac.jp

Received 5 October 2000

and in revised form

16 January 2001

Accepted 18 January 2001
Keywords: Hirayama disease; atopy; mite

Juvenile muscular atrophy of the distal upper limb (Hirayama disease) is a rare disease affecting primarily young men in the second to third decades. ${ }^{12}$ It is characterised by muscular atrophy and weakness in the hand and forearm, which is unilateral in most patients. ${ }^{2}$ The arrest follows several years after onset. ${ }^{2}$ The results of neuroimaging studies suggest the disorder to be a type of cervical myelopathy. ${ }^{2}$ Although postmortem findings disclosed disease is progressive initially, but spontaneous shrinkage and necrosis of the anterior horn cells of the spinal cord at C5 to T1, particularly marked at $\mathrm{C} 7$ and $\mathrm{C} 8,{ }^{3}$ the mechanism remains unknown.

Another rare disease is an acute poliomyelitis-like illness known as Hopkins' syndrome ${ }^{4}$ which presents as flaccid paralysis in one or more limbs after asthma attacks in childhood. We recently pointed out the importance of atopy as a background of this condition. ${ }^{5}$ Hirayama disease and Hopkins' syndrome differ in their patterns of onset, but are similar in their preponderance in young men, prominent anterior horn cell involvement, and absence of widespread lower motor neuron involvement. ${ }^{124}$ We therefore examined the atopic tendency in our consecutive patients with Hirayama disease.

Subjects and methods

SUBJECTS

During the past 2 years (September 1998 to August 2000), we examined five consecutive patients with Hirayama disease in the Department of Neurology at Kyushu University Hospital who showed typical neurological and neuroimaging findings. These five patients, three males and two females, were enrolled in the present study after informed consent was obtained. As controls for immunological studies, 82 healthy subjects (mean age (SD) 42 (10) years, 42 male and 40 female) were used.

\section{METHODS}

Cervical MRI was done in neutral and flexed positions as described previously. ${ }^{6}$ All patients were asked to describe their history of atopic and allergic disorders, such as bronchial asthma, atopic dermatitis, allergic rhinitis, pollinosis, allergic conjunctivitis, urticaria, and food, metal, and drug allergies. To obtain the control data, all outpatients in the neurology clinic from March 1998 to February 2000 were requested to complete the same questionnaire on their history of atopic and allergic disorders. Neurologically unremarkable patients who had no other medical diseases were grouped as normal controls, and the frequency of atopic and allergic disorders was determined in 81 neurologically normal controls. Total $\operatorname{IgE}$ in the serum was measured by an enzyme linked immunosorbent assay (ELISA) as described 
Table 1 Clinical and immunological findings of patients with Hirayama disease

\begin{tabular}{|c|c|c|c|c|c|}
\hline & \multicolumn{5}{|l|}{ Patient No } \\
\hline & 1 & 2 & 3 & 4 & 5 \\
\hline Age of onset (y) & 12 & 13 & 15 & 16 & 17 \\
\hline Age at examination (y) & 13 & 15 & 22 & 17 & 19 \\
\hline Sex & $\mathrm{F}$ & $\mathrm{F}$ & M & M & M \\
\hline Onset of neurological illness & Insidious & Insidious & Insidious & Insidious & Insidious \\
\hline Muscle atrophy of distal upper limb & $\mathrm{R}>\mathrm{L}$ & $\mathrm{R}$ & $\mathrm{R}<\mathrm{L}$ & $\mathrm{R}$ & $\mathrm{R}>\mathrm{L}$ \\
\hline \multicolumn{6}{|l|}{ Coexistent atopic/allergic disorders: } \\
\hline Bronchial asthma & $+\star \star$ & - & - & $(+) t$ & - \\
\hline Allergic rhinitis & - & + & + & + & - \\
\hline Pollinosis & - & - & + & - & - \\
\hline Atopic dermatitis & - & - & - & - & - \\
\hline others & + & - & - & - & - \\
\hline \multirow[t]{2}{*}{ Family history of atopic/allergic disorders } & Brother: AD & Father: pol & Father: AR & Father: AR & Brother: $\mathrm{AD}$ \\
\hline & $\begin{array}{l}\text { Sister: AD } \\
\text { Uncle: AR }\end{array}$ & Mother: pol & Brother: AR & Sister: AR & Sister: AD \\
\hline Peripheral blood eosinophils (\%) $\ddagger$ & 7.8 & 7.6 & 2.7 & 4.5 & 6.7 \\
\hline Serum total $\operatorname{IgE}(\mathrm{U} / \mathrm{ml})$ & 1874 & 1225 & 204 & 2400 & 150 \\
\hline \multicolumn{6}{|l|}{ Allergen specific IgE (IU/ml): } \\
\hline D pteronyssinus & 85.96 & $>100$ & 9.19 & $>100$ & 1.52 \\
\hline$D$ farinae & 90.66 & $>100$ & 7.75 & $>100$ & 2.63 \\
\hline Cedar pollen & - & 1.53 & 54.68 & 0.52 & - \\
\hline Soya bean & - & - & 0.38 & $\mathrm{NE}$ & - \\
\hline Others & - & - & - & $\mathrm{NE}$ & - \\
\hline
\end{tabular}

$\mathrm{UL}=$ Upper limb; $\mathrm{AD}=$ atopic dermatitis; $\mathrm{AR}=$ allergic rhinitis; pol=pollinosis; $\mathrm{NE}=$ not examined; $D=$ Dermatophagoides.

^Although patient 1 had asthma when she developed amyotrophy, the neurological illness occurred insidiously and showed no relation to asthma attacks.

†History of atopic/allergic disorders, which were not present at the time of neurological illness, is shown in parentheses.

‡Eosinophil percentage higher than $4 \%$ is considered abnormal.

previously. ${ }^{7}$ Two common mite antigens, Dermatophagoides farinae and $D$ pteronyssinus, cedar pollen, Candida, egg white, milk, wheat, rice, and soya bean were used for a liquid phase enzyme immunoassay (Ala-STAT, Sankoujunyaku, Tokyo). ${ }^{7}$ A serum IgE concentration higher than $250 \mathrm{U} / \mathrm{ml}$ was considered to be hyperIgEaemia. ${ }^{7}$ The cut off value for allergen specific IgE was $0.34 \mathrm{IU} / \mathrm{ml} .{ }^{7}$ Fisher's exact test was used for statistical analyses of the frequency of hyperIgEaemia and allergen specific $\operatorname{IgE}$.

\section{Results}

CLINICAL FINDINGS

The age of onset was 12 to 17 years old (mean (SD) 14.6 (1.9)), and the duration of the disease was 8 months to 7 years (2.5 (2.3) years) at the time of examination (table 1). All showed insidious onset of muscle atrophy and weakness confined to the distal part of the upper limbs, sparing the brachioradialis muscles (oblique atrophy). Two showed unilateral involvement and three showed bilateral but asymmetric involvement. No other neurological signs were seen in any patient. Needle EMG disclosed either ongoing or chronic neurogenic patterns in the atrophic muscles of all patients. Cervical MRI in a neutral position was normal in all patients, whereas that in flexion disclosed forward displacement of the dural sac together with passive dilatation of the posterior epidural venous plexus in all five patients (fig 1).

\section{IMMUNOLOGICAL FINDINGS}

Four of the five patients had coexistent atopic disorders (allergic rhinitis in three, asthma in one, and pollinosis in one (table 1)). Patient 4 had a history of asthma from 8 to 10 years old, and patient 1 had a food allergy, urticaria, and a history of allergic conjunctivitis. None of them had any history of atopic dermatitis. The frequencies of the history of allergic rhinitis and asthma in the normal controls were $13.6 \%$ $(11 / 81)$ and $4.9 \%(4 / 81)$, and thus the difference in frequency between the patients
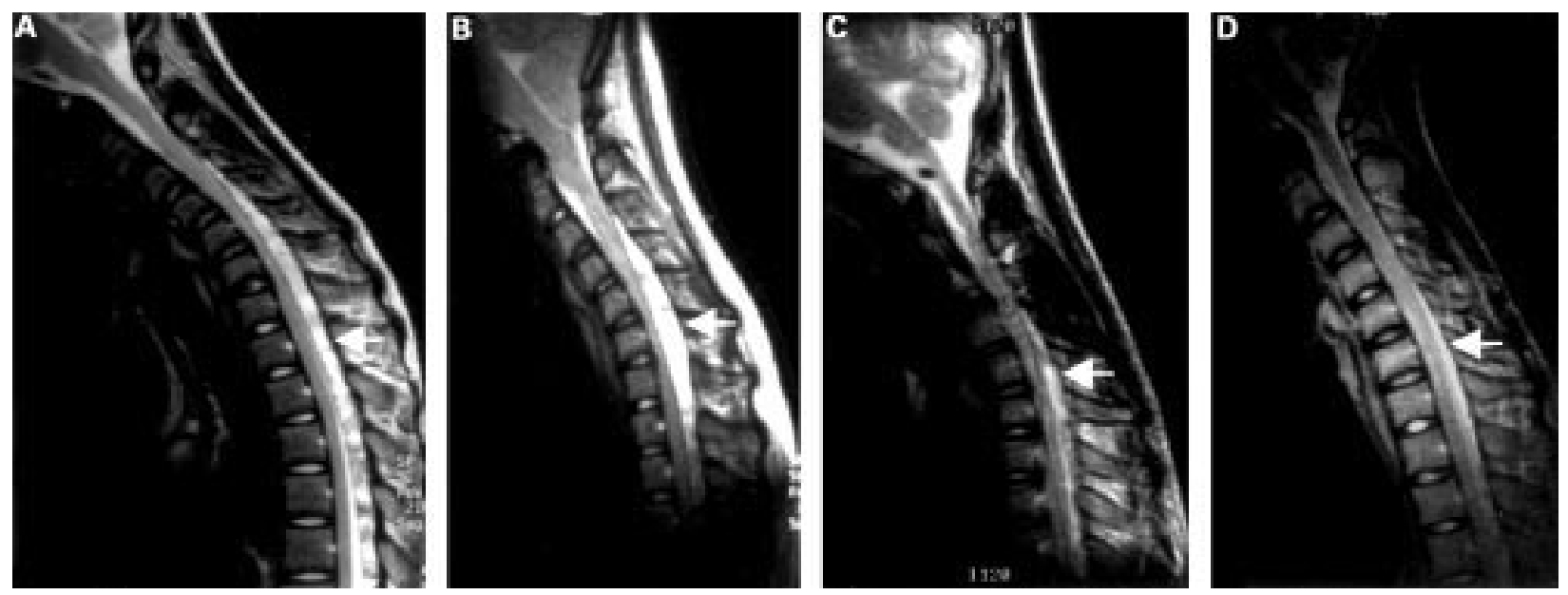

Figure 1 Cervical MRIs in a flexion position of patients with Hirayama disease and coexistent atopic and allergic disorders. $(A),(B),(C)$, and $(D)$ are patients 1, 2, 3, and 4, respectively. A crescent shaped high signal area is seen behind the spinal cord on T2 weighted images in all patients. 
with Hirayama disease and the normal controls were statistically significant for allergic rhinitis $(p=0.0288)$ and asthma $(p=0.0372)$. All five patients had a family history of atopic and allergic disorders in close relatives. The frequency of the family history of atopic and allergic disorders was thus significantly higher in the patients with Hirayama disease than in the controls $(14 / 81(17.3 \%) ; \mathrm{p}=0.0003)$.

Four of five patients had mild eosinophilia in the peripheral blood. HyperIgEaemia was present in three. All five patients shared IgE specific to the two mite antigens, three had IgE specific to cedar pollen, and one had $\operatorname{IgE}$ specific to soya bean. Specific IgE to other common allergens were not detected. The frequency of mite antigen specific IgE was significantly higher in patients with Hirayama disease than in the healthy controls ( $D$ pteronyssinus specific IgE, $5 / 5 v 26 / 82, \mathrm{p}=0.0046 ; D$ farinae specific IgE, 5/5 $v 25 / 82, p=0.0039)$ and that of hyperIgEaemia tended to be higher in the patients than in the controls (3/5 $v 17 / 82$, $\mathrm{p}=0.0774)$.

\section{Discussion}

This is the first immunological study to disclose the presence of atopy in patients with Hirayama disease. The high frequency of coexistent atopic disorders, hyperIgEaemia, and mite antigen specific IgE together with a family history of atopic or allergic disorders in the present patients strongly suggest the presence of an atopic tendency in Hirayama disease.

The high frequency of the forward displacement of the lower cervical dural sac and the flattening of the cord during neck flexion suggest a mechanical force working on the lower cervical cord as a contributory factor. ${ }^{2}$ Arrest of disease progression in several patients by wearing a cervical collar also supports this notion. ${ }^{8}$ However, several authors argue against it, because such a compression of lower cervical cord segments and increase in epidural space on neck flexion are seen in normal people. ${ }^{9}{ }^{10}$ In addition, we consider that the mechanical force hypothesis alone can hardly explain the the increase of Hirayama disease in the 1990s in Japan, spontaneous arrest of disease progression within 1 or 2 years after the onset, preponderance in young men, some unusual familial occurrences (either in siblings or in a father and a son), and preponderance in Asians. ${ }^{1-3}$ 9-11

Based on the neuropathological findings, some circulatory insufficiency was hyothesised. ${ }^{3}$ However, the shrinkage, necrosis, and degeneration of large and small neurons in the anterior horns differ from those seen in spinal vascular diseases. ${ }^{3}$ Thus, the nature of the microcirculatory insufficiency is not well understood.

There are several lines of evidence suggesting that atopy precipitates the occurrence of circulatory insufficiency, such as cardiovascular disease, especially in males. ${ }^{12}{ }^{13}$ IgE mediated antigenic response can produce platelet activation and aggregation, ${ }^{14}$ and $\operatorname{IgE}$ mediated release of histamine may produce arterial spasm in humans. ${ }^{15}$ Compression and venous stasis in the lower cervical cord after forward displacement of the dural sac may also locally precipitate such an IgE mediated platelet aggregation. Repeated microcirculatory disturbance may induce necrosis and degeneration of the anterior horn cells, which are the most vulnerable to ischaemia in the spinal cord. ${ }^{2}$ If the atopy is important as a background for Hirayama disease, a recent outbreak of atopic disorders in Japan should easily explain the increase of Hirayama disease whereas the familial occurrences of Hirayama disease may be related to the familial atopic tendency. Moreover, the finding that atopic disorders affect young people more than elderly people, ${ }^{16}$ males more than females, ${ }^{16}$ and Asians more than non-Asians ${ }^{17}$ may in part explain the epidemiological features of Hirayama disease.

The nature of Hopkins' syndrome is unknown, as there is no pathological study of this disease. We and others have shown hyperIgEaemia and allergen specific IgE in this disease and thus atopy itself may possibly have a pathogenic role. ${ }^{5}{ }^{18}$ It is interesting that asthma as well as allergic rhinitis-which predisposes to asthma - were the most frequent atopic disorders in the present patients and their families. Airway allergy, which is common in both Hopkins' syndrome and Hirayama disease, may thus predispose to anterior horn cell damage.

On the other hand, we recently reported occurrence of myelitis affecting preferentially the posterior column and presenting with paraesthesia and dysaesthesia in the distal parts of all four limbs in patients with atopic dermatitis and named it atopic myelitis. ${ }^{71}$ Atopic myelitis, Hopkins' syndrome, and Hirayama disease all share the important characteristic that myelitis or myelopathy develops in the presence of atopic disorders. This suggests a link between atopy and the development of spinal cord disease, although there is a difference in that skin allergy predisposes to posterior column damage whereas airway allergy predisposes to anterior horn cell damage.

Because our study comprises only a small case series, a further large scale study is necessary to clarify the relation between atopy and Hirayama disease. In the meantime, Hirayama disease progresses over several years, and the combined use of antiallergic drugs and a cervical collar may alleviate the syndrome.

This work was supported in part by grants from the neuroimmunological disease research committee and research on brain science from the Ministry of Health and Welfare, Japan, and grants in aid 12470142, 12557060, and 12877097 from the Ministry of Education, Science, Sports and Culture, Japan.

1 Hirayama K, Tsubaki T, Toyokura Y, et al. Juvenile muscular atrophy of unilateral upper extremity. Neurology 1963;13:373-80.

2 Hirayama K, Tokumaru Y. Cervical dural sac and spinal cord in juvenile muscular atrophy of distal upper extremity. Neurology 2000;54:1922-6.

3 Hirayama K, Tomonaga M, Kitano K, et al. Focal cervical poliopathy causing juvenile muscular atrophy of distal upper extremity: athological study 7 Neurol Neurosurg Psychiatry 1987;50:285-90.

4 Hopkins IJ. A new syndrome: poliomyelitis-like illness associated with acute asthma in childhood. Australian Paediatric fournal 1974:10:273-6.

5 Horiuchi I, Yamasaki K, Osoegawa M, et al. Acute myelitis after asthma attacks with onset after puberty. $\mathcal{F}$ Neurol Neurosurg Psychiatry 2000;68:665-8. 
6 Hasuo K, Uchino A, Matsumoto S, et al. Magnetic resonance imaging in a juvenile type of distal and segmental atrophy of the upper extremities. Eur Radiol 1994;4: $119-24$.

7 Kira J, Kawano Y, Yamasaki K, et al. Acute myelitis with hyperIgEaemia and mite antigen specific IgE: atopic myelitis. F Neurol Neurosurg Psychitary 1998;64:676-9.

8 Hirayama K. Juvenile muscular atrophy of distal upper extremity (Hirayama disease). Intern Med 2000;39:283-90.

9 Robberecht W, Aguirre T, Van den Bosch L, et al. Familial juvenile focal amyotrophy of the upper extremity (Hirayama disease). Superoxide dismutase I genotyping and activity. Arch Neurol 1997;54:46-50.

10 Schröder R, Keller E, Flacke S, et al. MRI findings in Hirayama's disease: flexion-induced cervical myelopathy or intrinsic motor neuron disease? 7 Neurol 1999;246:1069-74.

11 Sobue I, Saito N, Iida M, et al. Juvenile type of distal and segmental muscular atrophy of upper extremities. Ann

12 Criqui MH, Lee ER, Hamburger RN, et al. IgE and cardiovascular disease: results from a population-based study. $\mathrm{Am}$ 7 Med 1987;82:964-8.
13 Brunekreef B, Hoek G, Fischer P, et al. Relation between airbone pollen concentrations and daily cardiovascular and respiratory-disease mortality. Lancet 2000;355:1517-8.

14 Knauer KA, Lichtenstein LM, Adkinson NF, et al. Platelet activation during antigen-induced airway reactions in asthmatic subjects. N Engl F Med 1981;304:1404-7.

15 Ginsburg R, Bristow MR, Kantrowitz N, et al. Histamine provocation of clinical coronary artery spasm: implications poncerning pathogenesis of variant angina pectoris. Am Heart f 1981;102:819-22.

16 Sato K, Nakazawa T. Age related changes in specific IgE antibody production. Ann Allergy 1992;68:520-4.

17 Leung RC, Carlin JB, Burdon JG, et al. Asthma, allergy, and atopy in Asian immigrants in Melbourne. Med f Aust 1994; 161:418-25.

18 Mizuno Y, Komori S, Shigetomo R, et al. Poliomyelitis-like illness after acute asthma (Hopkins' syndrome). Brain Dev 1995;17:126-9.

19 Kira J, Yamasaki K, Kawano Y, et al. Acute myelitis associated with hyperIgEaemia and atopic dermatitis. $\mathcal{F}$ Neurol Sci 1997;148:199-203.

\section{$\overline{\text { HISTORICAL NOTE }}$}

\section{Aphasia or aphemia}

I remember reading the ancient use of the word aphemia instead of aphasia when a young student. Aphemia, I felt was a mellifluent, romantic word and wondered about its origin. Trousseau in his seventh lecture given at the Hôtel-Dieu, Paris, On Aphasia gives an interesting footnote. ${ }^{1}$

"The affection which I am about to describe was, in 1841 , termed alalia by Professor Lordat*; and in 1861, Mr Broca changed this name for that of aphemia. But Mr Chrysaphis, a very distinguished Greek scholar, and a Greek himself, although accepting the term alalia, proposed, however, as a better one that of aphasia, derived from a privative and, $\phi \alpha \sigma l \xi$ speech. $\mathrm{Mr}$ Littré, whose authority is so great, and Dr Briau have likewise preferred the word aphasia, and all three concur in rejecting aphemia. I had at first adopted the name of aphemia after Mr Broca, but I have now, on the authority of the savants whom I have mentioned, substituted for it that of aphasia."

J M S PEARCE

304 Beverley Road, Anlaby, Hull HU10 7BG, UK jmspearce@freenet.co.uk

1 Del'aphasie, maladie d'erite récemment sous le nom impropre d'aphémie. Gaz Hôp Paris nom impropre d'aphémie. $G a z$
$1864 ; 37: 13-14 ; 25-6 ; 37-9 ; 49-50$.

^ Lordat was himself a victim of aphasia; his experience are detailed in Trousseau's chapter. 